\title{
Treating sleep disorders to improve blood pressure control and cardiovascular prevention: a dream come true? - a narrative review
}

\author{
Giuseppe Maiolino ${ }^{1}$, Valeria Bisogni ${ }^{2}$, Alessandro Silvani ${ }^{3}$, Martino Francesco Pengo ${ }^{4}$, \\ Carolina Lombardi ${ }^{4,5}$, Gianfranco Parati ${ }^{4,5}$
}

${ }^{1}$ Clinica Medica 3, Department of Medicine - DIMED, University of Padova, Padova, Italy; ${ }^{2}$ Unit of Internal Medicine, Terni University Hospital, Terni, Italy; ${ }^{3}$ Department of Biomedical and Neuromotor Sciences, University of Bologna, Bologna, Italy; ${ }^{4}$ IRCCS Istituto Auxologico Italiano, Department of Cardiovascular, Neural and Metabolic Sciences, Milan, Italy; ${ }^{5}$ Faculty of Medicine, University of Milan-Bicocca, Milan, Italy

Contributions: (I) Conception and design: None; (II) Administrative support: None; (III) Provision of study materials or patients: None; (IV) Collection and assembly of data: None; (V) Data analysis and interpretation: None; (VI) Manuscript writing: All authors; (VII) Final approval of manuscript: All authors.

Correspondence to: Martino Francesco Pengo, MD, PhD. Department of Cardiovascular, Neural and Metabolic Sciences, IRCCS Istituto Auxologico Italiano, Ospedale San Luca, Via Magnasco, 2, Milan, Italy. Email: m.pengo@auxologico.it.

\begin{abstract}
Hypertension is one of the primary risk factors for heart disease and stroke, the leading causes of death worldwide. Current evidence supports the treatment of high blood pressure (BP) values in order to obtain a substantial reduction of cardiovascular burden. Sleep plays an important role in maintaining nocturnal BP control and nocturnal hypertension which, in turn, can be affected by the presence of sleep disorders. Whilst respiratory disturbances have been extensively studied and their causal role in the development of nocturnal hypertension has been demonstrated in both cross sectional and prospective studies, less is known about the impact of other sleep disorders such as insomnia. In this review, we aim to describe the role of sleep disorders in the development of nocturnal and diurnal hypertension. Furthermore, we aim to discuss the potential impact of the treatment of such sleep disorders on BP values as an adjunct treatment for patients with hypertension.
\end{abstract}

Keywords: Sleep disorders; hypertension; nocturnal blood pressure; therapy

Submitted Jul 07, 2020. Accepted for publication Sep 10, 2020.

doi: 10.21037/jtd-cus-2020-014

View this article at: http://dx.doi.org/10.21037/jtd-cus-2020-014

\section{Introduction}

Hypertension is the biggest single contributor to the global burden of cardiovascular disease and to global mortality (1). Interventions aimed at improving blood pressure (BP) control may thus exert substantial beneficial effects on the prevention of adverse cardiovascular events. Sleep plays an important role in maintaining nocturnal BP control through autonomic control of heart rate and peripheral vascular resistance $(2,3)$. In this review, we aim to discuss the evidence that respiratory and non-respiratory sleep disorders may compromise BP control also during daytime, leading to the development of arterial hypertension.
Furthermore, we aim to discuss the most recent evidence supporting the treatment of sleep disorders as an adjunct treatment for BP control. The review was based on PubMed-indexed studies published in English.

We present the following article in accordance with the Narrative Review Checklist (available at http://dx.doi. org/10.21037/jtd-cus-2020-014).

\section{Respiratory sleep disorders and BP}

Sleep-disordered breathing (SDB) has been extensively investigated with regard to its cardiovascular implications 
since the first reports of the association between snoring and hypertension $(4,5)$. Several research studies have now clarified how respiratory events during sleep can raise BP. However, such pathophysiological processes have been investigated and confirmed mainly for obstructive sleep apnoea (OSA), and less is known about central sleep apnoea (CSA) and other forms of SDB.

\section{$O S A$}

OSA is the most common form of SDB in developed countries and is associated with excessive daytime sleepiness and reduction of life quality $(6,7)$. Furthermore, OSA has been included as one of the causes of secondary hypertension in the most recent guidelines of the European Society of Cardiology (8) and is often associated to 'difficult-to-treat' high BP (9).

The pathophysiology of OSA is characterised by recurrent partial (hypopnoea) or complete (apnoea) episodes of upper airway collapse for at least 10 seconds associated with persistent breathing efforts (10). Such repetitive cycles of obstructive events lead to recurrent cycles of arterial hypoxia, hypercapnia, and re-oxygenation, frequent arousals with sleep fragmentation, and changes in the intrathoracic pressure (11). As a consequence, several effects related to increased $\mathrm{BP}$ values have been described: (I) increase of systemic inflammation, hypercoagulability, and oxidative stress, which result in higher levels of endothelin-1 and decreased nitric oxide production in endothelial cells, with increased arterial peripheral resistance and arterial stiffness (12); (II) sympathetic nervous system activation with higher secretion of plasma catecholamines that leads to increased cardiac output and peripheral vasoconstriction (13); (III) glucose metabolism dysfunction $(14,15)$ and deregulation of hypothalamic pituitary adrenal axis with increased plasma cortisol (16); (IV) higher renin secretion induced by efferent renal sympathetic nerve activation along with renin-angiotensin-aldosterone system overactivity and inappropriate sodium and fluid retention $(17,18)$.

These pathophysiological observations have been confirmed in epidemiological studies where OSAinduced high BP has been associated with developing and maintaining systemic arterial hypertension and cardiovascular comorbidities $(5,18,19)$. Moreover, evidence indicates a dose-effect relationship between the severity of OSA and the degree of hypertension. In the Wisconsin Sleep Cohort Study (WSCS), after adjusting for demographic and anthropometric variables, alcohol intake, and smoking, the odds ratio for hypertension comparing the highest category of apnoea-hypopnea index (AHI) with the lowest one $(\geq 30 / \mathrm{h} v s .<1.5 / \mathrm{h})$ was 1.37 (20). Interestingly, there are data suggesting that the link between OSA and hypertension is driven by the former during rapideye-movement (REM) sleep, mainly in the second half of the sleep period. In the WSCS, fully adjusted models demonstrated significant dose-relationships between REM sleep AHI and prevalent hypertension, whereas non-REM sleep AHI was not a significant predictor of hypertension $(21,22)$.

\section{CSA}

CSA is uncommon in the general population compared to OSA (23) but is common in specific subpopulations of patients, including those with heart failure $(24,25)$, stroke (26), and during opioids administration (27). CSA can be also diagnosed in other conditions, or can be defined as idiopathic, according to the International Classification of Sleep Disorders (3rd edition) (ICSD-3) (28). Furthermore, growing evidence $(29,30)$ suggests an overlap between CSA and OSA; more exactly, central events may represent instability of the breathing pattern, and this instability may provoke obstructive events, as suggested also by higher prevalence of CSA in males than in females $(31,32)$.

CSA is characterized by repeated episodes of airflow reduction or cessation ( $\geq 30 \%$ or $\geq 90 \%$ of pre-event baseline using nasal pressure, respectively) for at least 10 seconds but without respiratory effort, due to a transitory decrease or pause in central ventilatory drive during sleep (29). The polysomnographic criterion defining CSA is an AHI $>5$ events per hour of sleep, with more than $50 \%$ of apnoeas/ hypopnoeas being central in nature (28).

According to underlying pathological mechanisms and depending on $\mathrm{PaCO}_{2}$ levels, CSA can be classified into hypercapnic and normocapnic/hypocapnic forms, whereas, based on the respiratory pattern, it can be classified into cyclic/periodic and sustained or irregular types (30). These classifications should be considered for both identification of the underlying disease and decision on the appropriate ventilatory support $(26,29)$. Regardless of its complex pathophysiology, CSA triggers a cascade of acute physiological consequences, including arterial oxygen desaturation, which is usually less severe compared to OSA and may be accompanied by hypercapnia, post-apnoeic arousals from sleep and sleep fragmentation, increases in cardiac filling pressure and sympathetic activation, which 
can potentially aggravate the underlying disease and lead to an increased risk of cardiovascular events and mortality $(26,33,34)$. A close and potentially bidirectional relationship between CSA and heart failure $(35,36)$, stroke $(26,37)$, and atrial fibrillation (38) has been extensively established. Conversely, the specific effect of CSA and its treatment on arterial hypertension is incompletely explored. A significant increase of CSA and BP in normotensive and hypertensive patients with increasing altitude is well-documented (39-41). Recently, the HIGHCARE-Sestriere study (42) aimed to evaluate the effects of acute exposure of healthy volunteers to moderate altitude on BP values and on the frequency and severity of SDB. At altitude, both daytime and nighttime systolic and diastolic BP were significantly higher compared to sea level, and so was the AHI due to central apnoeic or hypopnoeic episodes. However, no association was found between BP changes and AHI. Previous studies performed at higher altitude $(43,44)$ did not detect a direct relationship between greater CSA severity and higher BP values, either. Given the complex pathophysiology of CSA, it is unclear whether these conclusions may be translated to CSA in patients with heart failure at sea level. Moreover, there is evidence that at least in children, CSA is associated with acute increases in BP and heart rate (45). Nevertheless, it seems fair to conclude that hypertension is more tightly associated with OSA rather than with CSA.

\section{Non-respiratory sleep disorders and BP}

As opposed to SDB, whose association with hypertension has been extensively studied, less consistent data are available on non-respiratory sleep alterations and sleeprelated disorders despite their widespread diffusion in the general population. Chronic sleep restriction with short sleep duration, insomnia, and circadian rhythm sleep disorders are among the most prevalent sleep alterations. Sleep alterations are also common in restless legs syndrome (RLS), which is a highly prevalent sensorimotor neurological disorder.

\section{Chronic sleep restriction with short sleep duration}

Chronic sleep restriction leading to short sleep duration ( $<7$ hours per night) (46) is an emerging problem worldwide and it has been estimated to affect one third of adults in the United States (47). Information on the BP effects of short sleep duration was provided by the CARDIA sleep study, which enrolled a cohort of 578 subjects who underwent an objective assessment of BP and sleep duration with three consecutive days of actigraphy. The CARDIA sleep study showed that short sleep duration was associated with significantly higher values of systolic and diastolic BP crosssectionally and predicted adverse changes in systolic and diastolic BP over 5 years. Strikingly, each hour of reduction in sleep duration was associated with a $37 \%$ increase in the odds of incident hypertension (48). More recent metaanalyses supported a link between short sleep duration and hypertension (49-54). Nonetheless, the association is still being debated, as shown by a recent cross-sectional study including 2,148 Hispanic subjects, the Sueño Sleep Ancillary Study of the Hispanic Community Health Study/Study of Latinos (HCHS/SOL), which did not confirm the association between sleep duration, measured by means of one week actigraphy, and self-reported hypertension diagnosis (55). In conclusion, short sleep duration appears to be associated with a higher BP, although there are inconsistencies among published studies. These inconsistencies may result from multiple factors including the self-reported $v s$. objective assessment of sleep duration (56) and hypertension, ethnicity, workday $v s$. weekend sleep duration, and individual differences in sleep need (46).

\section{Insomnia}

Insomnia is characterised by difficulties in initiating or maintaining sleep, or early awakening associated with a decreased wakefulness functioning (28). A large part of the population, e.g., 20-30\%, reports insomnia symptoms $(28,57)$, and chronic insomnia disorder affects $6-19 \%$ of the general population (58).

The association between insomnia and hypertension is still controversial, as recently reviewed (59). When insomnia definition was based on diagnostic criteria (28), insomnia was found to increase the risk of hypertension, defined as medication use or physician diagnosis, by $21-$ $24 \%(60,61)$ and to increase BP values $(62,63)$. However, other studies did not confirm this association (64-71). Similarly, studies assessing insomnia with objective short sleep duration reported an association with hypertension (72-74), with few exceptions (71). In conclusion, the link between insomnia and hypertension is still controversial, even when the former is accompanied by objective short sleep duration, suggesting either that the link is not robust or that it is strongly modulated by confounding factors that have been insufficiently taken into account in published work. 
Table 1 Prevalence of hypertension in different sleep disorders

\begin{tabular}{lll}
\hline Sleep disorder & Prevalence & $\begin{array}{l}\text { Hypertension prevalence odds ratio [95\% } \\
\text { confidence interval (CI)] }\end{array}$ \\
\hline $\begin{array}{l}\text { Obstructive sleep apnoea } \\
\text { syndrome }\end{array}$ & $\begin{array}{l}3-7 \% \text { of middle-aged men; 2-5\% of } \\
\text { middle-aged women }\end{array}$ & $1.37(1.03-1.83)(20)$ \\
Central sleep apnoea syndrome & Rare in the general population. & No increased odds of hypertension reported \\
Chronic insomnia & $6-19 \%$ of the general population & $3.5(1.6-7.9)$ for $5-6$ h of sleep duration; 5.1 \\
& & $(2.2-11.8)$ for $\leq 5$ h of sleep duration $(72)$ \\
Restless legs syndrome & $2-5 \%$ in the adult population & $1.36(1.18-1.57)(85-87)$ \\
Shift work sleep disorder & $1-4 \%$ of the active working population & $1.10(1.00-1.20)(77)$ \\
\hline
\end{tabular}

\section{Shift work sleep disorder}

Shift work sleep disorder affects up to one third of shift workers, also depending on the shifts schedule and the definition employed $(75,76)$. Shift work sleep disorder is characterized by insomnia symptoms or excessive sleepiness occurring transiently in relation to work schedules (75). The association between shift work sleep disorder and hypertension is still unclear. A recent metaanalysis published in 2017 including 27 studies and 394,793 participants found a significant association between rotating shift work and hypertension, but no significant association between night shift status and hypertension (77). Significant associations between night shifts and hypertension have been reported by more recent studies on subjects with rotational shifts, short shift intervals, and consecutive night shifts (78-80).

\section{$R L S$}

The RLS is a neurological sensorimotor disorder with a prevalence that ranges between $5.0 \%$ and $14.3 \%$ in the adult population (81). RLS is characterized by uncomfortable lower limbs sensations that usually occur before sleep onset and are relieved by legs movement $(28,82)$. RLS is commonly associated with periodic limb movements during sleep (PLMS) (83) and with sleep disturbances characterized by wakefulness that disrupts sleep onset and/or maintenance (82). The evidence concerning the link between RLS and hypertension has been considered as questionable or insufficient by a recent systematic review on the association between RLS and major diseases (84). Nevertheless, a retrospective study including 12,128 subjects diagnosed with RLS matched to more than 700,000 control subjects showed that primary as well as secondary RLS were associated with a $19-28 \%$ raised risk of incident hypertension (85). Moreover, a recent meta-analysis including 9 crosssectional studies with 102,408 RLS subjects found a $36 \%$ higher prevalence of hypertension in affected subjects compared to controls (86). In a retrospective study of 673 treated hypertensive patients, a frequency of RLS >2 episodes per week combined with PLMS $\geq 26 / \mathrm{h}$ doubled the odds of resistant hypertension (87). In conclusion, although the association of RLS and hypertension has been supported by multiple studies, it still represents a topic of debate, at least in part due to imperfect RLS diagnosis accuracy, confounding effects of comorbidities, and lack of longitudinal prospective data.

\section{Impact of sleep disorder treatment on BP}

The findings of the studies reviewed in the previous sections indicate that OSA is the sleep disorder most robustly associated with the development of hypertension (Table 1). Convincing evidence has shown that treating OSA leads to a significant although modest decrease in BP. Among the treatments for OSA, those that have been investigated with regard to their effect on $\mathrm{BP}$ are continuous positive airway pressure (CPAP) and mandibular advancement devices (MAD). Recent meta-analyses indicate a significant but small reduction of $\mathrm{BP}$ values in patients with OSA treated with CPAP $(21,88,89)$, with stronger effects on patients with resistant hypertension $(88,89)$ and on nocturnal $\mathrm{BP}$ values $(88,90)$. This is of interest because the role of nocturnal $\mathrm{BP}$ in the development of cardiovascular disease and its association with mortality and cardiovascular morbidity in both hypertensive patients and the general population have 
been confirmed in several longitudinal and populationbased studies $(2,91,92)$. In addition to higher baseline $\mathrm{BP}$ values, excessive daytime sleepiness and, particularly, greater treatment compliance are also associated with greater beneficial effects of CPAP treatment on BP (93). Insufficient treatment of OSA during REM sleep in the second half of the night may explain, at least in part, the key impact of treatment compliance on the CPAP effectiveness in decreasing $\mathrm{BP}$ values (21).

Oral devices are suggested for the treatment of mild-tomoderate OSA and their effect on BP values is promising and similar to that achieved with CPAP $(93,94)$. Recently, a comprehensive meta-analysis (95) including data from 68 randomized controlled trials that compared CPAP or MADs with either passive or active treatment showed that, when all the studies were pooled together, CPAP was associated with a mean $\mathrm{BP}$ reduction of -2.09 (95\% CI, -2.78 to -1.40$) \mathrm{mmHg}$ for systolic BP and -1.92 (95\% CI -2.40 to -1.43$) \mathrm{mmHg}$ for diastolic BP, whereas corresponding figures for MADs were -1.27 (95\% CI, -2.34 to -0.20$) \mathrm{mmHg}$ for systolic BP and -1.11 (95\% CI, -1.82 to -0.41$) \mathrm{mmHg}$ for diastolic BP. A subgroup analysis showed that patients with more elevated BP values pre-treatment, patients aged $<60$ years and patients with severe oxygen desaturations were more likely to exhibit a more pronounced BPlowering effect in response to CPAP treatment. The available data were considered insufficient to perform a corresponding stratified analysis for trials with MADs. Nevertheless, this study suggested that an accurate phenotypisation of OSA patients before treatment can help understand who can benefit the most in terms of $\mathrm{BP}$ reduction and therefore of cardiovascular protection. Conversely, current guidelines and recommendations support the treatment of OSA with the aim of reducing $\mathrm{BP}$, but do not define the phenotypes of the patients who would benefit most from this approach (10).

Other strategies for OSA treatment, such as invasive and non-invasive electrical stimulation of the upper airways, are emerging, but their role on BP control has been evaluated in only few studies, with encouraging results (96). Regarding medical therapy, the most promising class of antihypertensive drugs able to reduce both OSA severity and $\mathrm{BP}$ values are diuretics, especially mineralocorticoid receptors antagonists, whose beneficial effects in this setting are thought to result from lowering peripheral oedema and volume overload (97). Other classes of antihypertensive medications have been tested showing convincing results. Eskandari and co-authors showed that acetazolamide alone or in association with CPAP reduced $\mathrm{BP}$ values, vascular stiffness, and SDB in patients with OSA and comorbid hypertension (98). Moreover, Pépin and co-authors demonstrated, in a randomised controlled trial, that in patients with OSA, the treatment with valsartan allowed to obtain a greater $\mathrm{BP}$ reduction compared to $\mathrm{CPAP}$ alone not only during daytime but also during nighttime (99).

Nevertheless, the effect of these drugs on hypertension management in patients with OSA needs to be confirmed with multi-centre, large-sample studies with long follow-up periods. With regard to non-respiratory sleep alterations, a systematic review of the effects of sleep extension on cardiometabolic risk factors (100) listed only three smallscale studies that measured BP (101-103), none of which found a significant beneficial effect. On the other hand, a recent feasibility study that applied a technology-assisted behaviour intervention to extend sleep in adults with short sleep duration and prehypertension or stage 1 hypertension found significant BP reductions with treatment (104). Data on the beneficial effect of insomnia and RLS treatment on $\mathrm{BP}$ are also scarce. Huang et al. (105) showed a significant improvement of nocturnal BP values and of BP dipping profile in a group of BP non-dippers with poor sleep quality treated with zolpidem for 30 days. However, in this study, insomnia was not diagnosed according to AASM criteria, as patients were assessed with the Pittsburgh Sleep Quality Index only. Li and co-authors (106) assessed 556 patients with diagnosed insomnia and hypertension in a randomized, double-blinded and placebo-controlled clinical trial: patients assigned to estazolam, a triazolobenzodiazepine drug, achieved a better BP control compared to the control group $(74.8 \%$ vs. $50.5 \%, \mathrm{P}<0.001)$. On the other hand, a recent study found that suvorexant, a dual orexin receptor antagonist, had no overall effect on BP in patients with insomnia and treated hypertension (107). In patients with moderate to severe RLS, rotigotine significantly reduced PLMS-associated nocturnal BP elevations compared with placebo (108). Finally, studies about the effects of therapy of shift work sleep disorder on BP and hypertension are scarce. A recent Cochrane systematic review of pharmacological interventions for sleepiness and sleep disturbances caused by shift work highlighted the need for more and better quality trials on the beneficial and adverse effects and costs of all pharmacological agents that induce sleep or promote alertness in shift workers, both with and without a diagnosis of shift work sleep disorder. The review also noted that clinically relevant rises in BP were reported in 18\% of participants treated with armodafinil (109). 


\section{Conclusions}

The association between sleep disturbances and increased BP has been extensively studied both in respiratory and nonrespiratory sleep-related disorders. Convincing evidence for this association is available for OSA. There is also evidence suggestive of an association for chronic sleep restriction with short sleep duration, insomnia, and RLS, whereas evidence is still scarce for CSA and shift work sleep disorder. The treatment of OSA with CPAP and MADs has now been confirmed to be effective in reducing $\mathrm{BP}$, but more research is needed to understand effect predictors and, most importantly, to identify which patient phenotypes can benefit the most in terms of $\mathrm{BP}$ reduction with the aim to improve cardiovascular prevention. There is also limited evidence suggesting beneficial effects of insomnia and RLS therapy on BP. There is, therefore, an unmet need for well-designed, large-scale studies with sufficiently long follow-up to understand whether treatment of respiratory and non-respiratory sleep disorders can represent a new frontier for hypertension management and cardiovascular prevention. Importantly, these studies should include a thorough assessment of nocturnal BP, which plays a critical role in determining cardiovascular risk $(2,91,92)$, and which is more directly affected by sleep disorder therapy than daytime BP $(88,90,105,108)$. This "kill two birds with one stone" approach could allow clinicians to better control at least nocturnal BP while treating the underlining sleep disorder, thus ameliorating sleep quality, quality of life and cardiovascular outcomes. The mounting evidence supporting the association between sleep disorders and hypertension poses the question whether it is worth considering the treatment of sleep disorders as an adjunct or, in selected cases, as an alternative to the current plethora of antihypertensive medications.

\section{Acknowledgments}

Funding: None.

\section{Footnote}

Provenance and Peer Review: This article was commissioned by the Guest Editor (Joerg Steier) for the series " $5^{\text {th }}$ Clinical Update Sleep" published in Fournal of Thoracic Disease. The article was sent for external peer review organized by the Guest Editor and the editorial office.

Reporting Checklist: The authors have completed the
Narrative Review Checklist. Available at http://dx.doi. org/10.21037/jtd-cus-2020-014

Conflicts of Interest: All authors have completed the ICMJE uniform disclosure form (available at http://dx.doi. org/10.21037/jtd-cus-2020-014). The series " $5^{\text {th }}$ Clinical Update Sleep" was commissioned by the editorial office without any funding or sponsorship. GP reports personal fees from Omron Healthcare, personal fees from Sanofi, outside the submitted work. The other authors have no other conflicts of interest to declare.

Ethical Statement: The authors are accountable for all aspects of the work in ensuring that questions related to the accuracy or integrity of any part of the work are appropriately investigated and resolved.

Open Access Statement: This is an Open Access article distributed in accordance with the Creative Commons Attribution-NonCommercial-NoDerivs 4.0 International License (CC BY-NC-ND 4.0), which permits the noncommercial replication and distribution of the article with the strict proviso that no changes or edits are made and the original work is properly cited (including links to both the formal publication through the relevant DOI and the license). See: https://creativecommons.org/licenses/by-nc-nd/4.0/.

\section{References}

1. Gupta A, Mackay J, Whitehouse A, et al. Long-term mortality after blood pressure-lowering and lipid-lowering treatment in patients with hypertension in the AngloScandinavian Cardiac Outcomes Trial (ASCOT) Legacy study: 16-year follow-up results of a randomised factorial trial. Lancet 2018;392:1127-37.

2. Silvani A. Sleep disorders, nocturnal blood pressure, and cardiovascular risk: A translational perspective. Auton Neurosci 2019;218:31-42.

3. Bisogni V, Pengo MF, Maiolino G, et al. The sympathetic nervous system and catecholamines metabolism in obstructive sleep apnoea. J Thorac Dis 2016;8:243-54.

4. Lugaresi E, Cirignotta F, Coccagna G, et al. Some epidemiological data on snoring and cardiocirculatory disturbances. Sleep 1980;3:221-4.

5. Lombardi C, Pengo MF, Parati G. Systemic hypertension in obstructive sleep apnea. J Thorac Dis 2018;10:S4231-43.

6. Senaratna CV, Perret JL, Lodge CJ, et al. Prevalence of obstructive sleep apnea in the general population: A 
systematic review. Sleep Med Rev 2017;34:70-81.

7. Garvey JF, Pengo MF, Drakatos P, et al. Epidemiological aspects of obstructive sleep apnea. J Thorac Dis 2015;7:920-9.

8. Williams B, Mancia G, Spiering W, et al. 2018 ESC/ESH Guidelines for the management of arterial hypertension. Eur Heart J 2018;39:3021-104.

9. Parati G, Ochoa JE, Bilo G, et al. Obstructive sleep apnea syndrome as a cause of resistant hypertension. Hypertens Res 2014;37:601-13.

10. Epstein LJ, Kristo D, Strollo PJ, et al. Clinical guideline for the evaluation, management and long-term care of obstructive sleep apnea in adults. J Clin Sleep Med 2009;5:263-76.

11. Bradley TD, Floras JS. Obstructive sleep apnoea and its cardiovascular consequences. Lancet 2009;373:82-93.

12. Garvey JF, Taylor CT, McNicholas WT. Cardiovascular disease in obstructive sleep apnoea syndrome: The role of intermittent hypoxia and inflammation. Eur Respir J 2009;33:1195-205.

13. Narkiewicz K, Somers VK. Sympathetic nerve activity in obstructive sleep apnoea. Acta Physiol Scand 2003;177:385-90.

14. Murphy AM, Thomas A, Crinion SJ, et al. Intermittent hypoxia in obstructive sleep apnoea mediates insulin resistance through adipose tissue inflammation. Eur Respir J 2017;49:1601731.

15. Nagayoshi M, Punjabi NM, Selvin E, et al. Obstructive sleep apnea and incident type 2 diabetes. Sleep Med 2016;25:156-61.

16. Tomfohr LM, Edwards KM, Dimsdale JE. Is obstructive sleep apnea associated with cortisol levels? A systematic review of the research evidence. Sleep Med Rev 2012;16:243-9.

17. Prejbisz A, Kołodziejczyk-Kruk S, Lenders JWM, et al. Primary Aldosteronism and Obstructive Sleep Apnea: Is This A Bidirectional Relationship? Horm Metab Res 2017;49:969-76.

18. Parati G, Lombardi C, Hedner J, et al. Recommendations for the management of patients with obstructive sleep apnoea and hypertension. Eur Respir J 2013;41:523-38.

19. Javaheri S, Barbe F, Campos-Rodriguez F, et al. Sleep Apnea: Types, Mechanisms, and Clinical Cardiovascular Consequences. J Am Coll Cardiol 2017;69:841-58.

20. Nieto FJ, Young TB, Lind BK, et al. Association of sleepdisordered breathing sleep apnea, and hypertension in a large community-based study. JAMA 2000;283:1829-36.

21. Mokhlesi B, Finn LA, Hagen EW, et al. Obstructive sleep apnea during REM sleep and hypertension: Results of the Wisconsin sleep cohort. Am J Respir Crit Care Med 2014;190:1158-67.

22. Lombardi C, Parati G, Soranna D, et al. Periodic limb movements during sleep and blood pressure changes in sleep apnoea: Data from the European Sleep Apnoea Database. Respirology 2019. [Epub ahead of print].

23. Heinzer R, Vat S, Marques-Vidal P, et al. Prevalence of sleep-disordered breathing in the general population: THE HypnoLaus study. Lancet Respir Med 2015;3:310-8.

24. Randerath W, Schiza S, Deleanu O, et al. Central sleep apnoea and periodic breathing in heart failure: Prognostic significance and treatment options. Eur Respir Rev 2019;28:190084.

25. Yumino D, Wang H, Floras JS, et al. Prevalence and Physiological Predictors of Sleep Apnea in Patients With Heart Failure and Systolic Dysfunction. J Card Fail 2009; 15:279-85.

26. Baillieul S, Revol B, Jullian-Desayes I, et al. Diagnosis and management of central sleep apnea syndrome. Expert Rev Respir Med 2019;13:545-57.

27. Walker JM, Farney RJ, Rhondeau SM, et al. Chronic opioid use is a risk factor for the development of central sleep apnea and ataxic breathing. J Clin Sleep Med 2007;3:455-61.

28. Darien I. The international classification of sleep disorders (ICSD-3). American Academy of Sleep Medicine; 2014.

29. Randerath W, Verbraecken J, Andreas S, et al. Definition, discrimination, diagnosis and treatment of central breathing disturbances during sleep. Eur Respir J 2017;49:1600959.

30. Orr JE, Malhotra A, Sands SA. Pathogenesis of central and complex sleep apnoea. Respirology 2017;22:43-52.

31. Lombardi C, Meriggi P, Agostoni P, et al. High-altitude hypoxia and periodic breathing during sleep: Genderrelated differences. J Sleep Res 2013;22:322-30.

32. Lombardi C, Faini A, La Rovere MT, et al. Heart failure and sleep related breathing disorders: Data from PROMISES (Progetto Multicentrico Italiano Sonno e Scompenso Cardiaco) study. Int J Cardiol 2018;271:140-5.

33. Somers VK, White DP, Amin R, et al. Sleep apnea and cardiovascular disease: an American Heart Association/ American College of Cardiology Foundation Scientific Statement from the American Heart Association Council for High Blood Pressure Research Professional Education Committee, Council on Clinical Cardiology, Stroke Council, and Council on Cardiovascular Nursing. J Am Coll Cardiol 2008;52:686-717. 
34. Bradley TD, Floras JS. Sleep apnea and heart failure - Part II: Central sleep apnea. Circulation 2003;107:1822-6.

35. Selim BJ, Ramar K. Management of Sleep Apnea Syndromes in Heart Failure. Sleep Med Clin 2017;12:107-21.

36. Bradley TD, Logan AG, Kimoff RJ, et al. Continuous positive airway pressure for central sleep apnea and heart failure. N Engl J Med 2005;353:2025-33.

37. Alexiev F, Brill AK, Ott SR, et al. Sleep-disordered breathing and stroke: chicken or egg? J Thorac Dis 2018;10:S4244-52.

38. Tung P, Levitzky YS, Wang R, et al. Obstructive and central sleep apnea and the risk of incident atrial fibrillation in a community cohort of men and women. J Am Heart Assoc 2017;6:e004500.

39. Bärtsch P, Gibbs JSR. Effect of altitude on the heart and the lungs. Circulation 2007;116:2191-202.

40. Fowler AC, Kalamangalam GP. Periodic breathing at high altitude. IMA J Math Appl Med Biol 2002;19:293-313.

41. Whitelaw W. Mechanisms of sleep apnea at altitude. Adv Exp Med Biol 2006;588:57-63.

42. Torlasco C, Bilo G, Giuliano A, et al. Effects of acute exposure to moderate altitude on blood pressure and sleep breathing patterns. Int J Cardiol 2020;301:173-9.

43. Insalaco $\mathrm{G}$, Romano $\mathrm{S}$, Salvaggio A, et al. Blood pressure and heart rate during periodic breathing while asleep at high altitude. J Appl Physiol 2000;89:947-55.

44. Parati G, Bilo G, Faini A, et al. Changes in $24 \mathrm{~h}$ ambulatory blood pressure and effects of angiotensin II receptor blockade during acute and prolonged highaltitude exposure: A randomized clinical trial. Eur Heart J 2014;35:3113-22.

45. O'Driscoll DM, Foster AM, Ng ML, et al. Central apnoeas have significant effects on blood pressure and heart rate in children. J Sleep Res 2009;18:415-21.

46. Watson NF, Safwan Badr M, Belenky G, et al. Joint Consensus Statement of the American Academy of Sleep Medicine and Sleep Research Society on the Recommended Amount of Sleep for a Healthy Adult: Methodology and Discussion. Sleep 2015;38:1161-83.

47. Ford ES, Cunningham TJ, Croft JB. Trends in SelfReported Sleep Duration among US Adults from 1985 to 2012. Sleep 2015;38:829-32.

48. Knutson KL, Van Cauter E, Rathouz PJ, et al. Association between sleep and blood pressure in midlife: The CARDIA sleep study. Arch Intern Med 2009;169:1055-61.

49. Meng L, Zheng Y, Hui R. The relationship of sleep duration and insomnia to risk of hypertension incidence: A meta-analysis of prospective cohort studies. Hypertens Res 2013;36:985-95.

50. Guo X, Zheng L, Wang J, et al. Epidemiological evidence for the link between sleep duration and high blood pressure: A systematic review and meta-analysis. Sleep Med 2013;14:324-32.

51. Wang Q, Xi B, Liu M, et al. Short sleep duration is associated with hypertension risk among adults: A systematic review and meta-analysis. Hypertens Res 2012;35:1012-8.

52. Han B, Chen WZ, Li YC, et al. Sleep and hypertension. Sleep Breath 2020;24:351-6.

53. Itani O, Jike $M$, Watanabe $N$, et al. Short sleep duration and health outcomes: a systematic review, meta-analysis, and meta-regression. Sleep Med 2017;32:246-56.

54. Wang Y, Mei H, Jiang YR, et al. Relationship between duration of sleep and hypertension in adults: A metaanalysis. J Clin Sleep Med 2015;11:1047-56.

55. Ramos AR, Weng J, Wallace DM, et al. Sleep Patterns and Hypertension Using Actigraphy in the Hispanic Community Health Study/Study of Latinos. Chest 2018;153:87-93.

56. Lauderdale DS. Sleep duration: how well do self-reports reflect objective measures? The CARDIA Sleep Study. Epidemiology 2008;19:838-45.

57. American Psychiatric Association. American Psychiatric Association: Diagnostic and Statistical Manual of Mental Disorders Fifth Edition. Arlington; 2013.

58. Riemann D, Baglioni C, Bassetti C, et al. European guideline for the diagnosis and treatment of insomnia. J Sleep Res 2017;26:675-700.

59. Jarrin DC, Alvaro PK, Bouchard MA, et al. Insomnia and hypertension: A systematic review. Sleep Med Rev 2018;41:3-38.

60. Lin CL, Liu TC, Lin FH, et al. Association between sleep disorders and hypertension in Taiwan: A nationwide population-based retrospective cohort study. J Hum Hypertens 2017;31:220-4.

61. Clark AJ, Salo P, Lange T, et al. Onset of Impaired Sleep and Cardiovascular Disease Risk Factors: A Longitudinal Study. Sleep 2016;39:1709-18.

62. Lanfranchi PA, Pennestri MH, Fradette L, et al. Nighttime blood pressure in normotensive subjects with chronic insomnia: Implications for cardiovascular risk. Sleep 2009;32:760-6.

63. Wang Y, Jiang T, Wang X, et al. Association between Insomnia and Metabolic Syndrome in a Chinese Han Population: A Cross-sectional Study. Sci Rep 
2017;7:10893.

64. Cellini N, de Zambotti M, Covassin N, et al. Working memory impairment and cardiovascular hyperarousal in young primary insomniacs. Psychophysiology 2014;51:206-14.

65. Sivertsen B, Lallukka T, Salo P, et al. Insomnia as a risk factor for ill health: Results from the large populationbased prospective HUNT Study in Norway. J Sleep Res 2014;23:124-32.

66. Giahi O, Khoubi J, Amiri M. The association between insomnia and cardiovascular risk factors in bus drivers in Iran. Work 2016;55:207-14.

67. Wang YM, Song M, Wang R, et al. Insomnia and multimorbidity in the community elderly in China. J Clin Sleep Med 2017;13:591-7.

68. Floam S, Simpson N, Nemeth E, et al. Sleep characteristics as predictor variables of stress systems markers in insomnia disorder. J Sleep Res 2015;24:296-304.

69. Uhlig BL, Sand T, Ødegård SS, et al. Prevalence and associated factors of DSM-V insomnia in Norway: The Nord-Trøndelag Health Study (HUNT 3). Sleep Med 2014;15:708-13.

70. Chen IY, Jarrin DC, Ivers H, et al. Investigating psychological and physiological responses to the Trier Social Stress Test in young adults with insomnia. Sleep Med 2017;40:11-22.

71. Johann AF, Hertenstein E, Kyle SD, et al. Insomnia with objective short sleep duration is associated with longer duration of insomnia in the Freiburg Insomnia Cohort compared to insomnia with normal sleep duration, but not with hypertension. PLoS One 2017;12:e0180339.

72. Vgontzas AN, Liao D, Bixler EO, et al. Insomnia with objective short sleep duration is associated with a high risk for hypertension. Sleep 2009;32:491-7.

73. Bathgate CJ, Edinger JD, Wyatt JK, et al. Objective but Not Subjective Short Sleep Duration Associated with Increased Risk for Hypertension in Individuals with Insomnia. Sleep 2016;39:1037-45.

74. Fernandez-Mendoza J, Vgontzas AN, Liao D, et al. Insomnia with objective short sleep duration and incident hypertension: The Penn State Cohort. Hypertension 2012;60:929-35.

75. Drake CL, Roehrs T, Richardson G, et al. Shift work sleep disorder: Prevalence and consequences beyond that of symptomatic day workers. Sleep 2004;27:1453-62.

76. Di Milia L, Waage S, Pallesen S, et al. Shift Work Disorder in a Random Population Sample - Prevalence and Comorbidities. PLoS One 2013;8:e55306.
77. Manohar S, Thongprayoon C, Cheungpasitporn W, et al. Associations of rotational shift work and night shift status with hypertension: A systematic review and meta-analysis. J Hypertens 2017;35:1929-37.

78. Ferguson JM, Costello S, Neophytou AM, et al. Night and rotational work exposure within the last 12 months and risk of incident hypertension. Scand J Work Environ Health 2019;45:256-66.

79. Cho YS, Lee S, Yoon JH, et al. Short rest between shifts and risk of hypertension in hospital workers. J Hypertens 2020;38:211-7.

80. Khosravipour M, Shah Mohammadi M, Valadi Athar H, et al. The association between rotating night shift work and hypertension: A cross-sectional study among male workers. Eur J Prev Cardiol 2020. [Epub ahead of print].

81. Ohayon MM, O'Hara R, Vitiello MV. Epidemiology of restless legs syndrome: A synthesis of the literature. Sleep Med Rev 2012;16:283-95.

82. Allen RP, Picchietti DL, Garcia-Borreguero D, et al. Restless legs syndrome/Willis-Ekbom disease diagnostic criteria: Updated International Restless Legs Syndrome Study Group (IRLSSG) consensus criteria - history, rationale, description, and significance. Sleep Med 2014;15:860-73.

83. Montplaisir J, Boucher S, Poirier G, et al. Clinical, polysomnographic, and genetic characteristics of restless legs syndrome: A study of 133 patients diagnosed with new standard criteria. Mov Disord 1997;12:61-5.

84. Trenkwalder C, Allen R, Högl B, et al. Restless legs syndrome associated with major diseases: A systematic review and new concept. Neurology 2016;86:1336-43.

85. Van Den Eeden SK, Albers KB, et al. Risk of Cardiovascular Disease Associated with a Restless Legs Syndrome Diagnosis in a Retrospective Cohort Study from Kaiser Permanente Northern California. Sleep 2015;38:1009-15.

86. Shen Y, Liu H, Dai T, et al. Association between restless legs syndrome and hypertension: a meta-analysis of nine population-based studies. Neurol Sci 2018;39:235-42.

87. Hein M, Lanquart JP, Hubain P, et al. Risk of resistant hypertension associated with restless legs syndrome and periodic limb movements during sleep: a study on 673 treated hypertensive individuals. Sleep Med 2019;63:46-56.

88. Hu X, Fan J, Chen S, et al. The Role of Continuous Positive Airway Pressure in Blood Pressure Control for Patients With Obstructive Sleep Apnea and Hypertension: A Meta-Analysis of Randomized Controlled Trials. J Clin Hypertens (Greenwich) 2015;17:215-22. 
89. Iftikhar IH, Valentine CW, Bittencourt LRA, et al. Effects of continuous positive airway pressure on blood pressure in patients with resistant hypertension and obstructive sleep apnea: A meta-analysis. J Hypertens 2014;32:2341-50.

90. Schein ASO, Kerkhoff AC, Coronel CC, et al. Continuous positive airway pressure reduces blood pressure in patients with obstructive sleep apnea; A systematic review and meta-analysis with 1000 patients. J Hypertens 2014;32:1762-73.

91. Hansen TW, Li Y, Boggia J, et al. Predictive role of the nighttime blood pressure. Hypertension 2011;57:3-10.

92. Hermida RC, Crespo JJ, Otero A, et al. Asleep blood pressure: Significant prognostic marker of vascular risk and therapeutic target for prevention. Eur Heart J 2018;39:4159-71.

93. Torres G, Sánchez-De-La-Torre M, Barbé F. Relationship between OSA and hypertension. Chest 2015;148:824-32.

94. Iftikhar IH, Hays ER, Iverson MA, et al. Effect of oral appliances on blood pressure in obstructive sleep apnea: A systematic review and meta-analysis. J Clin Sleep Med 2013;9:165-74.

95. Pengo MF, Soranna D, Giontella A, et al. Obstructive sleep apnoea treatment and blood pressure: Which phenotypes predict a response? A systematic review and meta-analysis. Eur Respir J 2020;5 5:1901945.

96. Strollo PJ, Soose RJ, Maurer JT, et al. Upper-airway stimulation for obstructive sleep apnea. N Engl J Med 2014;370:139-49.

97. Gaddam K, Pimenta E, Thomas SJ, et al. Spironolactone reduces severity of obstructive sleep apnoea in patients with resistant hypertension: A preliminary report. J Hum Hypertens 2010;24:532-7.

98. Eskandari D, Zou D, Grote L, et al. Acetazolamide Reduces Blood Pressure and Sleep-Disordered Breathing in Patients With Hypertension and Obstructive Sleep Apnea: A Randomized Controlled Trial. J Clin Sleep Med 2018;14:309-17.

Cite this article as: Maiolino G, Bisogni V, Silvani A, Pengo MF, Lombardi C, Parati G. Treating sleep disorders to improve blood pressure control and cardiovascular prevention: a dream come true?-a narrative review. J Thorac Dis 2020;12(Suppl 2):S225-S234. doi: 10.21037/jtd-cus-2020-014
99. Pépin JL, Tamisier R, Barone-Rochette G, et al. Comparison of continuous positive airway pressure and valsartan in hypertensive patients with sleep apnea. Am J Respir Crit Care Med 2010;182:954-60.

100.Henst RHP, Pienaar PR, Roden LC, et al. The effects of sleep extension on cardiometabolic risk factors: A systematic review. J Sleep Res 2019;28:e12865.

101. Kubo T, Takahashi M, Sato T, et al. Weekend sleep intervention for workers with habitually short sleep periods. Scand J Work Environ Health 2011;37:418-26.

102. Haack M, Serrador J, Cohen D, et al. Increasing sleep duration to lower beat-to-beat blood pressure: A pilot study. J Sleep Res 2013;22:295-304.

103. Reynold AM, Bowles ER, Saxena A, et al. Negative Effects of Time in Bed Extension: A Pilot Study. J sleep Med Disord 2014;1:1002.

104. Baron KG, Duffecy J, Richardson DJ, et al. Technology assisted behavior intervention to extend sleep among adults with short sleep duration and prehypertension/stage 1 hypertension: A randomized pilot feasibility study. J Clin Sleep Med 2019;15:1587-97.

105.Huang Y, Mai W, Cai X, et al. The effect of zolpidem on sleep quality, stress status, and nondipping hypertension. Sleep Med 2012;13:263-8.

106. Li Y, Yang Y, Li Q, et al. The impact of the improvement of insomnia on blood pressure in hypertensive patients. J Sleep Res 2017;26:105-14.

107. Kario K, Yamasaki K, Yagi K, et al. Effect of suvorexant on nighttime blood pressure in hypertensive patients with insomnia: The SUPER-1 study. J Clin Hypertens (Greenwich) 2019;21:896-903.

108. Bauer A, Cassel W, Benes H, et al. Rotigotine's effect on PLM-associated blood pressure elevations in restless legs syndrome. Neurology 2016;86:1785-93.

109. Liira J, Verbeek JH, Costa G, et al. Pharmacological interventions for sleepiness and sleep disturbances caused by shift work. Cochrane Database Syst Rev 2014;(8):CD009776. 